\title{
A Conceptual Model of eLearning Adoption
}

\author{
doi:10.3991/ijet.v6iS2.1652 \\ Muneer Abbad \\ Prince Mohammad Bin Fahd University, Saudi Arabia
}

\begin{abstract}
Internet-based learning systems are being used in many universities and firms but their adoption requires a solid understanding of the user acceptance processes. The technology acceptance model (TAM) has been used to test the acceptance of various technologies and software within an e-learning context. This research aims to discuss the main factors of a successful e-learning adoption by students. A conceptual research framework of e-learning adoption is proposed based on the TAM model.
\end{abstract}

Index Terms-Conceptual model, e-learning, e-learning adoption

\section{INTRODUCTION}

The study of technology adoption has been considered among researchers in the IT community (e.g. Grandon and Pearson, 2004; Vailer et al., 2004). The information systems literature contains multiple models of factors that are associated with IT use or acceptance. The main research streams that have been developed in the area of information technology acceptance studies are the theory of reasoned action (TRA) (Fishbein and Ajzen, 1975), the theory of planned behaviour (TPB) (Ajzen, 1985), the innovation diffusion theory (IDT) (Rogers, 1983), the technology acceptance model (TAM) (Davis, 1986), and the theoretical extension of TAM known as TAM2 (Venkatesh and Davis, 2000).

By building on existing work in the field, this research is, in part, an attempt to continue the cumulative tradition in information systems research. The TAM (Davis, 1989) was chosen as a framework to determine the factors that affect student's adoption of e-learning systems for the following reasons:

1. TAM has empirical evidence in explaining technology acceptance (Hu et al., 1999).

2. Previous research suggested that TAM could be an appropriate model to examine a student's acceptance of learning environment applications over a period of time (Carswell and Venkatesh, 2002; Stoel and Lee, 2003).

3. TAM is one of the most widely used models for IT adoption (Gefen and Straub, 2000; Gefen, 2003; Stoel and Lee, 2003).

4. TAM has been used as a theoretical basis for many empirical studies and has accumulated a great deal of support (Venkatesh and Davis, 2000; Van Slyke et al., 2003).

5. Researchers have employed the TAM model to help understand website usage (Teo et al., 1999; Moon and Kim, 2001) which is an application which has some similarities with (web-based) e-learning.

Davis (1989) stated that the goal of TAM is to provide a basis for tracing the impact of external factors on inter- nal beliefs, attitudes, and intention to use computers. TAM model posits that two particular beliefs, perceived usefulness (PU) and perceived ease of use (PEOU) are of the primary relevance for computer acceptance behaviours. External factors provide the bridge between the internal beliefs, attitudes and intentions represented in TAM and the various individual differences, situational constraints and managerially controllable interventions impinging on behaviour. Researchers have extended TAM by proposing and testing specific factors to its two-use belief constructs (PU and PEOU). As explained by Mathieson (1991: 173), without external factors TAM provides very general information on users' opinions about a system, but does not yield "specific information that can better guide system development". This study followed that line of reasoning and included not only the core determinants of TAM but also other sets of factors that may affect the students' adoption of e-learning systems.

\section{EMPIRICAL STUDIES USING TAM IN E-LEARNING}

Stoel and Lee (2003) used the TAM model as a framework to study the effect of student experience with webbased learning technologies on their acceptance of those technologies. They suggested that student experience with the technologies might influence their acceptance. The results showed that student experience with the technology positively influenced usage through the perceived usefulness and perceived ease of use. Similarly, Selim (2003) used the TAM model to assess students' acceptance of course websites as an effective learning tool. The results showed that course website usefulness and ease of use proved to be key determinants of the acceptance and usage of course websites as an effective learning tool. Lee et al. (2003) used the TAM model to examine the use of integrated communication and engineering design tools in a distributed learning environment. The TAM model was utilized to investigate the attitude formation process. With the TAM model, they were able to demonstrate that students' initial expectations affected the perceptions of attitude and use of the system. Khaled et al. (2004) added some external factors (e.g. gender and income) to the TAM model that may be considered in the academic environment. The results showed that gender; traditional vs. non-traditional students' categories, educational background, and classification (full-time vs. part-time) were not significant factors in affecting students' computer usage. However, income, computer knowledge, perceived ease of use, perceived usefulness, computer literacy, and attitudes were significant factors that affected students' computer usage. Pituch and Lee (2006) proposed and tested alternative models that seek to explain student intention to use an e-learning system when the system is used as a supplementary learning tool within a traditional class or a stand-alone distance education method. The models integrated determinants from TAM as well as sys- 
tem and participant characteristics cited in the research literature. In addition, their study represents an initial step in highlighting specific system factors that appear to promote system use and identifying how such system factors impact use of an e-learning system for both supplementary learning and distance education purposes. Given the increasing use of e-learning systems, a better understanding and implementation of effective system characteristics will enhance the use and educational value of such a system. In addition, Saadé and Bahli (2005) used an extended version of the TAM, including cognitive absorption (called intrinsic motivation). Their study intended to provide insight for improving the proposed model in the elearning context. The results provided support for the model as explaining acceptance of an online learning system and for cognitive absorption as a variable, which influences TAM variables. Ngai et al. (2007) extended the TAM model to include technical support as a precursor and then investigated the role of the extended model in user acceptance of WebCT. The results showed that technical support has a significant direct effect on perceived ease of use and usefulness, while perceived ease of use and usefulness are the dominant factors affecting the attitude of students using WebCT. In addition, the results indicate the importance of perceived ease of use and perceived usefulness in mediating the relationship of technical support with attitude and WebCT usage.

\section{FACtORs AfFecting StUdents’ Adoption of E- LEARNING SYSTEMS}

Based on the previous discussions, the two constructs, perceived ease of use and perceived usefulness, were the mediating constructs in attitudes towards web-based technology. Perceived ease of use will positively influence perceived usefulness and attitude for the web-based technology, and perceived usefulness will positively influence attitude and intention to use the technology. Attitude will positively influence intention to use, and intention to use will positively influence the actual web-based technology usage. In addition, researcher has looked at other factors influencing the adoption of web-based technology in different industries.

\section{A. Subjective Norm (SN)}

Davis et al. (1989) believed that in some cases people might use a system to comply with others' mandates rather than their own feelings and beliefs. Adler (1996) stated that social pressure could affect behaviour of individuals in varying degrees in different societies depending on the culture. In terms of technology acceptance, individuals from a collectivist culture may use computers because of the perceived social pressure from superiors and peers. Empirical support for the relationship between social norms and behaviour can be found in many studies (e.g. Tornatsky and Klein, 1982; Venkatesh and Davis, 2000). Individuals can choose to perform a specific behaviour even if they are not positive towards the behaviour or its consequences. The choice depends on how important the individuals think that the important referents believe that they should act in a certain way (e.g. Fishbein and Ajzen, 1975, Venkatesh and Davis, 2000). Unfortunately, early research on the TAM dropped SN as it showed insignificant results in affecting intention. Although, recently Lee (2006) found that the effects of SN significantly influenced perceived usefulness. In the e-learning context, Kim et al. (2005) suggested that SN influences the learner's satisfaction with and motivation for elearning. In addition, the SN was a significant prediction of students' satisfaction (Gunawardena and Zittle, 1997). Frith (2002) found that social factors enhanced students; motivation and satisfaction.

\section{B. Internet Experience (IE)}

Research studies suggest that prior experience is important in an individual's acceptance of IT. For example, Igbaria et al. (1995) found that prior experience is one of the factors explaining individual differences in technology acceptance research. Additionally, prior experience was found as strongly influencing intention to use and usage of a specific system through perceived ease of use (Agarwal and Prasad, 1999) and through perceived usefulness (Jiang et al., 2000). Igbaria et al. (1995) found that computer experience directly and indirectly influences microcomputer usage behaviour through perceived usefulness and perceived ease of use. As O'Cass and Fenech (2003) point out, when Internet users have accumulated sufficient personal experience via their adoption of computer technology, it creates a belief in their ability to use the Internet for learning purposes. Kerka (1999) stated that, in distance learning in Cyber space, learner success depends on technical skills in computer operation and Internet navigation, as well as the ability to cope with technical difficulty. Morss (1999) found empirical evidence that older students, who had more experience of the technology, use the system more than younger students with less experience do in non-WebCT classes. Conrad (2002) found that students who had more experience in e-learning courses were less likely to feel anxious about e-learning. Similarly, Arbaugh and Duray (2002) found that students who had more experience in e-learning course were more likely to be satisfied with e-learning systems. Researches using TAM have proposed that an individual's experiences with a specific technology influence perceptions of ease of use and usefulness of that technology. Selim (2003) suggested that a student's course website use tended to be greater when the site was viewed as being useful and easy to use. Thus, as student experience with a technology increases, they perceive it to be easier to use and more useful, and therefore, are more likely to use it. Based on evidence from prior TAM research, students' experience with webbased learning technology was conceptualized as an exogenous (external) variable. In addition, to explain user beliefs concerning usefulness and ease of use toward elearning systems, prior experience on the Internet has to be considered.

\section{System Interactivity (SI)}

Research suggests that system characteristics can influence the intention to use and usage behaviour of the system. For example, Bates (1991) noted that the main advances in distance education would come from technology that allowed increased learner interaction. Two types of interaction would be provided by a web-based learning system: instructor-to-student and student-to-student interactions. Palloff and Pratt (1999: 5) stated, "the key elements of learning processes are the interactions among students themselves, the interactions between faculty and students, and the collaboration in learning that results from these interactions". Some tools are used to facilitate the interactions, such as discussion forums, chat systems, and e-mail. In addition, the interactions can be either 
asynchronous or synchronous. In asynchronous discussions, there is no time and space constraint for any party and students are able to engage in discussions on diverse topics with facilitators and peers. The availability of interactive applications such as discussion forums and e-mail facilitate the interactivity. Duffy et al. (1998) stated that asynchronous learning environments foster students' information processing and critical thinking by allowing them the time to process their thinking when they post a message in an online environment. Additionally, the asynchronous learning environment is the preferable method for fostering in-depth student-rich interactions (Bonk et al., 1998). There is a significant relationship between interactivity and learning effectiveness. Henson et al. (2003) found that asynchronous discussions were effective in facilitating case studies in e-learning classes. Similarly, Mills and Salloway (2001) found that synchronous discussions are effective in e-learning classes. Students often chose different methods such as synchronous and asynchronous to complete different kinds of tasks in e-learning classes. Alhabshi (2002) stated that a web-based learning (WBL) environment should combine both synchronous and asynchronous communication to support various elements such as text, graphics, audio and video messages. Poon et al. (2004) found that students' grades are highly correlated with student's interactivity. Because of that, system interactivity is expected to be one of the factors that may affect students' adoption of e-learning systems.

\section{Self-Efficacy (SE)}

Self-efficacy is a belief in an individual's capability to perform certain behaviours or it is one's personal beliefs about his or her ability to perform certain tasks successfully (Bandura, 1986, 1997). Perceived self-efficacy refers to the beliefs in one's capability to organize and execute the courses of action required to produce a given accomplishment or outcome and originates from various sources including performance accomplishments, vicarious experience, verbal persuasion, and psychological states. Self-efficacy was one of the important beliefs in the social learning theory (Bandura, 1986, 1997). Several studies found that self-efficacy perceptions influenced decisions about what behaviours to undertake, persistence in attempting certain behaviours, and the actual performance attainments of the individual with respect to behaviour (Bandura, 1977; Brown and Inouye, 1978; Iocke et al., 1984; Wood and Bandura, 1989). With respect to Internetrelated tasks, self-efficacy can be an important factor in considering whether a new process is adopted (O'Cass and Fenech, 2003). Davis et al. (1989) and Venkatesh and Davis (1996) suggested that self-efficacy is an antecedent of perceived ease of use and object use ability. Compeau and Higgins (1995) also found that computer self-efficacy was a significant determinant of behavioural intention to use information technology. Similarly, Hill et al. (1987) reported that computer self-efficacy was a significant determinant of behavioural intentions. Dishaw et al. (2002: 1024) stated, "self-efficacy constructs have been widely used in the educational literature to study academic performance". Lu and Hsiao (2007) and Rao and Troshani (2007) used computer self-efficacy as a proxy for an individual's internal control in the IT usage context. Lim (2000) stated that computer self-efficacy predicts future participation adult learners web-based distance education. Thong et al's (2002) study of digital libraries concluded that computer self-efficacy, computer experience, and domain knowledge affect perceived ease of use significantly in TAM. Similarly, Agarwal et al. (2000) found that self-efficacy is an important determinant of perceived ease of use. In the e-learning context, self-efficacy is interpreted as one's self-confidence in his or her ability to perform certain learning tasks using an e-learning system. For example, students with high sense of an educational self-efficacy believe that they can study using e-learning system. While, students with a low sense of educational self-efficacy believe they cannot study using an e-learning system. A student who has a strong sense of his or her capability in dealing with an e-learning system has a more positive perception of ease of use and usefulness and he or she is more willing to accept and use the system. A student's self-efficacy affects her/his actual behaviour decision or intention toward the educational process as well as their specific educational activities.

\section{E. Technical Support (TS)}

Ralph (1991) defined technical support as people assisting the users of computer hardware and software products, which can include hotlines, online support service, machine-readable support knowledge bases, faxes, automated telephone voice response systems, remote control software and other facilities. Technical support is one of the important factors in the acceptance of technology for teaching (Sumner and Hostetler, 1999; Hofmann, 2002; Williams, 2002) and in user satisfaction (Mirani and King, 1994). High levels of organizational support, including management support and information center support, were thought to promote more favourable attitudes about the system among users and information specialists, and lead to greater success for personal computing systems (Igbaria, 1994). Vandenbosch and Higgins (1995) study founded that training and prior computer experiences had a significant impact on system use. Technical support from the university is essential for achieving significant success in applying information technology in learning. In addition, technical support is especially important in the beginning stage of technology adoption. Hadley and Sheingold (1993) noted the importance of the day-to-day help with problems of time, space, supervision, operation, and access must be addressed to accomplish teachers' successful information technology adoption in schools through staff development and technical support. Selim (2003) grouped the e-learning critical success factors within a university environment into four categories: instructors, student, information technology, and university support. Igbaria et al. (1997) argued the internal and external personal computing support/training affected the acceptance of personal computing in small firms. Elearning projects that were not successful in achieving their goals did not have access to technical advice and support (Alexander and Mckenzie, 1998; Soong et al., 2001). If technical support is lacking, e-learning will not succeed (Selim, 2003). Selim's (2003) study showed that students indicated that they would register in future elearning based courses assuring their positive attitude and support to e-learning technology and tools. In addition, technical support is the major contributor to the effectiveness of the web-based learning system. Recently, Ngai et al. (2007) extended the TAM to include technical support as a precursor and investigated the role of the extended model in user acceptance of WebCT. The result showed that technical support has a significant direct effect on perceived ease of use and usefulness, while perceived ease 


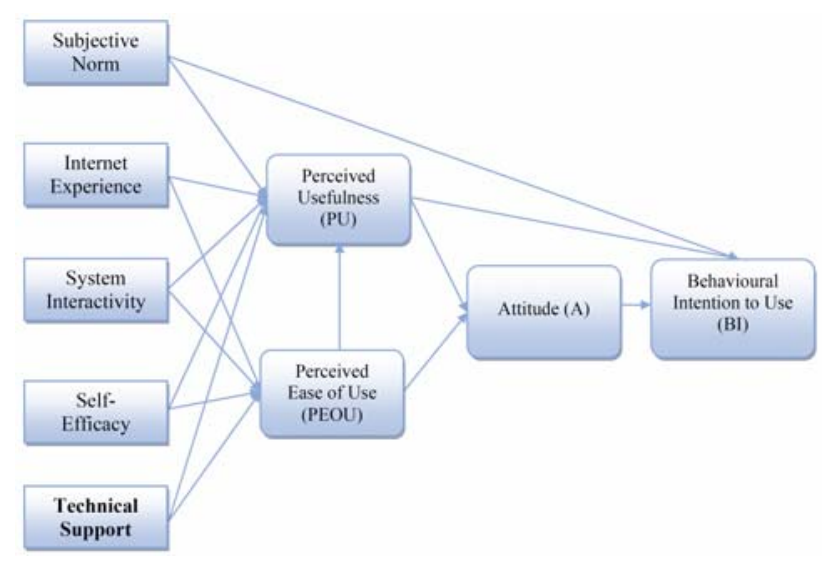

Figure 1. Proposed Model I

of use and usefulness are the dominant factors affecting the attitude of students using WebCT. In addition, the results indicated the importance of perceived ease of use and perceived usefulness in mediating the relationship of technical support with attitude and WebCT usage. In this study, technical support is expected to be one such external factor affecting the acceptance of e-learning systems.

Finally, the extension of the TAM is validated by its highlighting of the strength of the chosen external variables (subjective norm, system interactivity, self-efficacy, Internet experience, and technical support). One of the main results of this study is developing an extended versions of the TAM model in the e-learning context, called Proposed Model I and Proposed Model II (see Figure 1 and Figure 2). TAM posits that two particular beliefs, PEOU and PU are of the primary relevance for computer acceptance behaviours, but in addition, TAM proposed that the more the user perceives a new technology to be easy to use and useful, the stronger will be their attitude towards the technology and greater will be their intention to use the technology (Proposed Model I). TAM postulates that usage is determined by behavioural intention, based on that, this study proposed model II (Proposed Model II, Figure 2) to include actual use of e-learning systems. Proposed Model II has advantages similar to the TAM in that it identifies the significant effect of specific factors on students' intention to use and actual use of information technology. Since the factors in Proposed Model II were not present in the TAM, it might be able to provide a more complete understanding of usage in elearning contexts.

\section{SUMMARY AND CONCLUSION}

The main purpose of this paper is to gain an understanding of the existing theories and models in the field of user acceptance and to identify existing evidence that may lend support to the proposed model structure. The literature review provides a background of how users' acceptance has been studied in the IT field in general, and in elearning field in specific. In addition, this paper provides evidence to choose the baseline model that is used to determine the important factors that may affect students' adoption of e-learning systems. The TAM provides a sound framework for further research of the acceptance of e-learning systems. It posits that perceived usefulness and perceived ease of use mediate the relationship between external variables and behavioural intention to use system. Research indicates that external variables such as subjec-

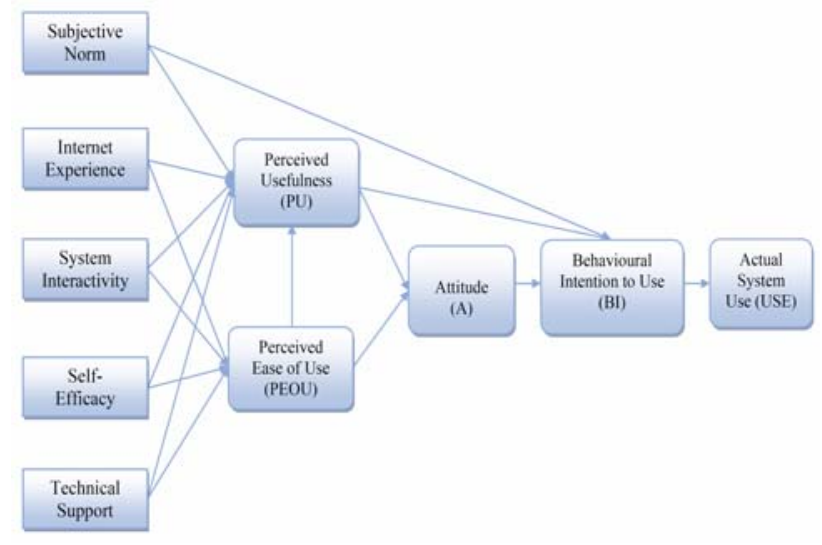

Figure 2. Proposed Model II

tive norms, Internet experience, system interactivity, selfefficacy and technical support have an influence upon technology acceptance.

\section{REFERENCES}

[1] Adler, R. (1996) Older adults and computers: Report of a national survey [online] available from <http:/www.seniornet.org/ php/default.php?PageID=5476\&Version $=0$ \& Font $=$ oFrissen $>[15$ December 2005].

[2] Agarwal, R. and Prasad, J. (1999) 'Are individual differences germane to the acceptance of new information technologies?' Decision Sciences 30, (2) 361-91. doi:10.1111/j.1540-5915. 1999.tb01614.x

[3] Aggarwal, A. (2000) Web-based learning and teaching technologies: Opportunities and challenges. London: Idea Group Pub.

[4] Alexander, S. and McKenzie, J. (1998) An Evaluation of Information Technology Projects in University Learning. Department of Employment, Education and Training and Youth Affairs, Canberra: Australian Government Publishing Services.

[5] Arbaugh, J.B. and Duray, R. (2002) 'Technological and structural characteristics, student learning and satisfaction with Web-based courses: An exploratory study of two online MBA programs.' Management and Learning 33, (3) 331-347. doi:10.1177/1350507602333003

[6] Bandura, A. (1986) Social Foundations of Thought and Action: A Social Cognitive Theory. Englewood Cliffs: NJ: Prentice Hall.

[7] Bandura, A. (1997) 'Self-efficacy: toward a unifying theory of behavioral change.’ Psychological Review 82, (2) 191-215.

[8] Banga, S. and Downing, K. J. (2000) Moving towards global education in the twenty-first century. Abramson, M., Towards the Global University: Reading Excellence in the Third Millennium, University of Central Lancashire, Preston.

[9] Bates, A. W. (1991) 'Third generation distance education: The challenge of new technology.' Research in Distance Education 3, (2) $10-16$.

[10] Bonk, C. J. and Cunningham, D. J. (1998) Searching for learnercentered, constructivist, and socio-cultural components of collaborative educational learning tools. New Jersey: Lawrence Erlbaum Associated, Publishers.

[11] Carswell, A. D. and Venkatesh, V. (2002) 'Learner outcomes in an asynchronous distance educational environment.' International Journal of Human-Computer Studies 56, (5) 475-494. doi:10.1006/ijhc.2002.1004

[12] Compeau, D.R. and Higgins, C.A. (1995) 'Computer self-efficacy: Development of a measure and initial test.' Management Information Systems Quarterly 19, (2) 189-211. doi:10.2307/249688

[13] Conrad, D.L. (2002) 'Conrad, Engagement, excitement, anxiety, and fear: Learners' experiences of starting an online course.' American Journal of Distance Education 16, (4) 205-226. doi:10.1207/S15389286AJDE1604_2

[14] Czerniak, C. Lumpe, A., Haney, J. and Beck, J. (1999) 'Teachers' beliefs about using educational technology in the science classroom.' International Journal of Educational Technology [online] 1, 
(2), available from <http://www.ascilite.org.au/ajet/ijet/v1n2/ czerniak/index.html> [10 July 2007].

[15] Davis, F. D. (1986) A technology acceptance model for empirically testing new end-user information systems: Theory and results. (Doctoral dissertation, Sloan School of Management, Massachusetts Institute of Technology).

[16] Davis, F. D., Bagozzi, R. P. and Warshaw, P. R. (1992) 'Extrinsic and intrinsic motivation to use computers in the workplace.' Journal of Applied social Psychology 22, (14) 1111-1122. doi:10.1111/j.1559-1816.1992.tb00945.x

[17] Davis, F.D. (1989) 'Perceived usefulness, perceived ease of use, and user acceptance of information technology.' MIS Quarterly 13, (3) 319-340. doi:10.2307/249008

[18] Davis, F.D. (1993) 'User acceptance of information technology: system characteristics, user perceptions and behavioral impacts.' International Journal of Man-Machine Studies 38, (1) 475-87. doi:10.1006/imms.1993.1022

[19] Dishaw, M. T., Strong, D. M. and Bandy, D. B. (2002) 'Extending task-technology fit model with self-efficacy constructs.’ HumanComputer Interaction Studies in MIS, (1) 1021-1026.

[20] Fishbein, M. and Ajzen, I. (1975) Belief, attitude, intention and behavior: An introduction to theory and research. Reading, MA: Addison-Wesley.

[21] Frith, K. H. (2002) Effect of conversation on nursing student outcomes in a Web-based course on cardiac rhythm interpretation. Doctoral dissertation, Georgia State University, Atlanta.

[22] Gay, G. and Lentini, M. (1995) 'Use of communication resources in a networked collaborative design Environment.' Journal of Computer Mediated Communication [online] 1, (1) available from

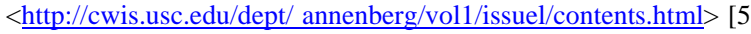
July 2007].

[23] Gefen, D. (2003) 'TAM or just plain habit: A look at experienced online shoppers.' Journal of End User Computing15, (3) 1-13. doi:10.4018/joeuc.2003070101

[24] Gefen, D. and Straub, D. (2000) 'The relative importance of perceived ease of use in IS adoption: A study of e-commerce adoption.' Journal of the Association for Information Systems 1, (8) 130.

[25] Gunawardena C.N. and Zittle, F.J. (1997) 'Social presence as a predictor of satisfaction within a computer-mediated conferencing environment.' American Journal of Distance Education 11, (3) 826. doi:10.1080/08923649709526970

[26] Hadley, M. and Sheingold, K. (1993) 'Commonalties and distinctive patterns in teachers' integration of computers.' American Journal of Education 101, (3) 261-315. doi:10.1086/444044

[27] Hasan, H. and Ditsa, G. (1998) 'The Impact of Culture on the Adoption of IT: An Interpretive Study.' Journal of Global Information Management 7, (1) 5-15.

[28] Hofmann, D.W. (2002) 'Internet-based distance learning in higher education.' Tech Directions 62, (1) 28-32.

[29] Igbaria, M., Gamers, T. and Davis, G.B. (1995) 'Testing the determinants of micro-computer usage via a structural equation model.' Journal of Management Information Systems 11, (4) 87 114.

[30] Jiang, J.J., Hsu, M.K., Klein, G. and Lin, B. (2000) 'E-commerce user behavior model: an empirical study.' Human Systems Management19, (4) 265-276.

[31] Kerka, S. (1999) Distance learning, the Internet, and the World Wide Web. ERIC Digest, ERIC Document Reproduction Service No. ED 395214.

[32] Kim, K., Liu, S. and Bonk, C.J. (2005) 'Online MBA students' perceptions of online learning: Benefits, challenges, and suggestions.' The Internet and Higher Education 8, (4) 335-344. doi:10.1016/j.iheduc.2005.09.005

[33] Lee, Y.C. (2006) 'An empirical investigation into factors influencing the adoption of an e-learning system.' Online Information Review 30, (5) 517-541. doi:10.1108/14684520610706406

[34] Lu, H. and Hsiao, k. (2007) 'Understanding intention to continuously share information on weblogs.' Internet Research17, (4) 4366.

[35] Mahmood, M. A., Hall, L. and Swanberg, D. L. (2001) 'Factors Affecting Information Technology Usage: A Meta-Analysis of the Empirical Literature.' Journal of Organizational Computing and
Electronic Commerce 11, (2) 107-130. doi:10.1207/ S15327744JOCE1102 02

[36] Mathieson, K. (1991) 'Predicting user intentions: comparing the Technology Acceptance Model with the theory of planned behavior.' Information Systems Research 2, (3) 173-191. doi:10.1287/isre.2.3.173

[37] Merriam, S. B. (1998) Case Study Research in Education: A Qualitative Approach. San Francisco, CA: Jossey-Bass Publishers.

[38] Mirani R. and King, W.R. (1994) 'Impacts of end-user and information center characteristics on end-user computing support.' Journal of Management Information Systems 11, (1) 141-166.

[39] Moon, J. and Kim, Y. (2001) 'Extending the TAM for a World Wide Web Context.' Information and Management 38, (4) 217231. doi:10.1016/S0378-7206(00)00061-6

[40] Morgan, D. (1996) 'Focus Groups.' Annual Reviews Inc 22, 129152.

[41] Ngai, E.W.T., Poon, J.K.L. and Chan, Y.H.C. (2007) 'Empirical examination of the adoption of WebCT using TAM.' Computers and Education 48, (2) 250-267. doi:10.1016/j.compedu. $\underline{2004.11 .007}$

[42] O’cass A. and Fenech, T. (2003) 'Web retailing adoption: exploring the nature of internet users Web retailing behavior.' Journal of Retailing and Consumer Services 10, (1) 81-94. doi:10.1016/ S0969-6989(02)00004-8

[43] Palloff R.M. and Pratt, K. (1999) Building learning communities in cyberspace: Effective strategies for the online classroom. Jossey-Bass Publishers, San Francisco, CA.

[44] Pituch, K. A. and Lee, Y. (2006) 'The influence of system characteristics on e-learning use.' Computers and Education 47, (2) 222244. doi:10.1016/j.compedu.2004.10.007

[45] Poon, W., Low, K. L. and Yong, D. G. (2004) 'A study of Webbased learning (WBL) environment in Malaysia.' The International Journal of Educational Management 18, (6) 374-385. doi:10.1108/09513540410554031

[46] Ralph, W. (1991) The art f computer technical support. California: Peachipt Press.

[47] Rao, S. and Troshani, I. (2007) 'A conceptual framework and propositions for the acceptance of mobile services.' Journal of Theoretical and Applied Electronic Commerce Research 2, (2) 6173.

[48] Rosenberg, M.J. (2001) E-learning: Strategies for delivering knowledge in the digital age. New York: McGraw-Hill.

[49] Saadé, R. and Bahli, B (2005) 'The impact of cognitive absorption on perceived usefulness and perceived ease of use in on-line learning: an extension of technology acceptance model.' Information and Management 42, (2) 317-327.

[50] Selim, H.M. (2003) 'An empirical investigation of student acceptance of a course websites.' Computers and Education 40, (4) 343360. doi:10.1016/S0360-1315(02)00142-2

[51] Soong, M.H.B., Chan H.C., Chua, B.C. and Loh, K.F. (2001) 'Critical success factors for on-line course resources.' Computers and Education 36, (2) 101-120. doi:10.1016/S0360-1315(00) 00044-0

[52] Stoel, L. and Lee, K. H. (2003) 'Modeling the effect of experience on the student acceptance of web-based courseware.' Internet research: Electronic Network Applications and Policy 13, (5) 364374. doi:10.1108/10662240310501649

[53] Sumner M. and Hostetler, D. (1999) ' Factors influence the adoption of technology in teaching.' Journal of Computer Information Systems 40, (1) 81-87.

[54] Szajna, B. (1996) 'Empirical evaluation of the revised technology acceptance model.' Management Science 42, (1) 85-92. doi:10.1287/mnsc.42.1.85

[55] Teo, T., Lim, V. and Lai, R. (1999) 'Intrinsic and extrinsic motivation in Internet usage.' Omega International Journal of Management 27, (1) 25-37.

[56] Tornatsky, L.G. and Klein, K.J. (1982) 'Innovation characteristics and innovation adoption-implementation: a meta-analysis of findings.’ IEEE Transactions on Engineering Management,(1) 28-45.

[57] Veiga, J. F., Floyd, S. and Dechant, K. (2001) 'Towards modeling the effects of national culture on IT implementation and accep- 
SPECIAL FOCUS PAPER

\section{A CONCEPTUAL MODEL OF ELEARNING ADOPTION}

tance.' Journal of Information Technology 16, (1) 145-158. doi:10.1080/02683960110063654

[58] Venkatesh, V. (2000) 'Determinants of perceived ease of use: integrating control, intrinsic motivation, and emotion into the technology acceptance model.' Information Systems Research 11, (4) 342-365. doi:10.1287/isre.11.4.342.11872

[59] Venkatesh, V. and Davis, F. (2000) 'A theoretical extension of the technology acceptance model: four longitudinal field studies.' Management Science 46, (2) 186-204. doi:10.1287/mnsc.46. $\underline{2.186 .11926}$

[60] Venkatesh, V. and Davis, F.D. (1996) 'A model of the antecedents of perceived ease of use: development and test.' Decision Sciences 27, (3) 451-481. doi:10.1111/j.1540-5915.1996.tb01822.x

[61] WEF (2003) World Economic Forum: Report 2003. [online]

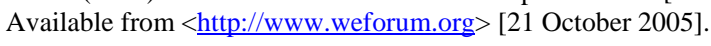

[62] Williams, P. (2002) 'The Learning Web: the development, implementation, and evaluation of Internet-based undergraduate materials for the teaching of key skills.' Active Learning in Higher Education 3, (1) 40-53. doi:10.1177/1469787402003001004

\section{AUTHOR}

Muneer Abbad is with Prince Mohammad Bin Fahd University, Saudi Arabia (mabbad@pmu.edu.sa).

This article is an extended version of a paper presented at the IEEE EDUCON20211 Conference, held from April 4th-6th, 2011, in Amman, Jordan. Received April $29^{\text {th }}$, 2011. Published as resubmitted by the author May $2^{\text {nd }}, 2011$. 